\title{
Um Diagnóstico das Práticas do Processo Gerência de Portfólio de Projetos em Organizações de Software de Belém
}

\author{
Maurício Ronny de Almeida Souza ${ }^{1}$, Antônio André C. da Silva ${ }^{2}$, Ariane dos S. \\ Sinimbú ${ }^{2}$, Sandro Ronaldo Bezerra Oliveira ${ }^{1,2}$, Alexandre M. Lins de Vasconcelos ${ }^{3}$ \\ ${ }^{1}$ Programa de Pós-Graduação em Ciência da Computação (PPGCC) - Universidade \\ Federal do Pará (UFPA) \\ ${ }^{2}$ Curso de Bacharelado em Ciência da Computação - Faculdade de Computação, \\ Instituto de Ciência Exatas e Naturais, Universidade Federal do Pará (UFPA) \\ ${ }^{3} \mathrm{CIn}$ - Centro de Informática, Universidade Federal de Pernambuco (UFPE) \\ \{mauricio.ronny, aandrecunhas, nanesinimbu\}@gmail.com, srbo@ufpa.br \\ amlv@cin.ufpe.br
}

\begin{abstract}
This paper describes a questionnaire application based study, inspired in the expected results of Project Portfolio Management process from $M R-M P S$, in order to identify the availed practices related to this process in software development organizations. A qualitative analysis was made of the results, in order to identify most common practices and main deficiencies related to the given models and quality standards' propositions.
\end{abstract}

Resumo. Este artigo descreve um estudo baseado na aplicação de um questionário, inspirado nos resultados esperados do processo de Gerência de Portfólio de Projetos do MR-MPS, a fim de identificar as práticas utilizadas para o referido processo em organizações desenvolvedoras de software. Uma análise qualitativa foi realizada sobre os resultados de modo a identificar as práticas mais comuns e as principais deficiências em relação ao que é proposto por modelos e normas de qualidade.

\section{Introdução}

O ambiente de negócios atual é complexo e requer decisões rápidas, eficientes e confiáveis. De frente a constantes mudanças tecnológicas, competitividade, prazos curtos e outras variáveis adversas, a prosperidade e sobrevivência da organização está diretamente ligada aos investimentos realizados [COOPER et al., 2001]. Em organizações de software não é diferente.

Dessa forma, a adoção da gerência de portfólio de projetos é imprescindível para uma organização, e define critérios para a seleção dos projetos em conformidade com a estratégia organizacional, realizando a priorização e iniciando os projetos selecionados, avaliando-os continuamente para garantir que continuam satisfazendo os interesses organizacionais, e decidindo por mantê-los, adiá-los, cancelá-los ou suspendê-los, conforme necessidade [LEVINE, 2005].

A crescente importância dada à gestão de portfólio, nos últimos anos, no contexto da indústria de software pode ser evidenciada pela recente adição, em 2008, do processo de Gestão de Portfólio de Projetos na Norma ISO/IEC 12207:2008 [ABNT, 2009], seguida da incorporação, em 2009, do Processo de Gerência de Portfólio de 
Projetos (GPP) no Modelo de Referência do MPS.BR (MR-MPS) [SOFTEX, 2009], seguida de uma atualização em 2011 [SOFTEX, 2011].

Este artigo apresenta uma pesquisa de campo, com caráter exploratório qualitativa, realizada em organizações de software localizadas na região metropolitana de Belém do Pará, acerca da aplicação de práticas de Gestão de Portfólio de Projetos. Para isto um questionário foi definido a partir dos resultados esperados do processo de GPP do MR-MPS [SOFTEX, 2009], para extrair informações que permitissem análise dos procedimentos para a seleção e priorização de projetos, alocação de recursos organizacionais, e acompanhamento do portfólio de projetos, em relação a critérios, técnicas e ativos envolvidos.

A partir dos resultados obtidos, uma análise comparativa é realizada em relação a um conjunto de boas práticas para a Gerência de Portfólio de Projetos, definido por Souza et al. (2011), extraído a partir de um mapeamento das práticas sugeridas pelo MR-MPS, pela norma ISO/IEC 12207:2008 e pelo Padrão para Gerência de Portfólio do PMI [PMI, 2008].

Além da seção introdutória, este artigo é organizado da seguinte forma: a Seção 2 aponta trabalhos relacionados; a Seção 3 descreve a metodologia aplicada na condução da pesquisa de campo, bem como da análise dos resultados e as restrições do trabalho; a Seção 4 analisa os resultados obtidos com os questionários; a Seção 5 apresenta a comparação dos resultados com o mapeamento de práticas supracitado; e, por fim, a Seção 6 apresenta as conclusões do trabalhos, relatando dificuldades encontradas, lições aprendidas e trabalhos futuros.

\section{Trabalhos Relacionados}

Os principais trabalhos relacionados à investigação sobre a aplicação da disciplina de gestão de portfólio de projetos na industria considerados neste trabalho são as pesquisas de Cooper et al. (2001) e Costa et al. (2010).

Cooper et al. (2001) apresentam os resultados da aplicação de um questionário em empresas participantes de um estudo a respeito de aplicação de melhores práticas de gerenciamento. Neste trabalho, os autores apontam as principais ferramentas, métodos e modelos aplicadas no gerenciamento de portfólio de projetos destas organizações, analisando o sucesso de cada item avaliado.

Em Costa et al. (2010) um estudo experimental baseado na realização de um Survey foi conduzido para tentar traçar o perfil de maturidade tanto em Gerência de Portfólio quanto no processo de seleção e balanceamento do portfólio de empresas de software brasileiras. Para tal, o estudo adotou o Modelo de Maturidade em Gerência de Portfólio da PM Solutions. Os resultados da pesquisa apontaram um baixo nível de maturidade em gestão de portfólio no cenário nacional, e concluiu que empresas de software, que pretenderem se adequar a normas e padrões e adotarem a Gerência de Portfólio como forma de alcançar seus objetivos estratégicos, precisam realizar ações de curto, médio e longo prazo a fim de atingirem níveis mais altos de maturidade.

A pesquisa conduzida neste trabalho pretende investigar como a gestão de portfólio de projetos é praticada em organizações de software, levando em consideração a baixa maturidade, neste contexto, no cenário nacional apontada por Costa et al. (2010). Assim, realizar um diagnóstico a partir da aplicação de um questionário 
inspirado nos Resultados Esperados do processo de GPP do MR-MPS [SOFTEX, 2009] e identificar as principais práticas adotadas. Não é objetivo desta pesquisa avaliar a maturidade das organizações, conforme já realizado por Costa et al. (2010) e nem verificar a eficiência das práticas e procedimentos adotados, conforme realizado por Cooper et al. (2001), mas sim realizar uma breve comparação do que é realizado com o que é sugerido como boa prática pelo modelo MR-MPS e outros padrões para gestão de portfólio.

\section{Metodologia}

Para a condução deste estudo, foi realizada uma pesquisa de campo, com caráter exploratório, por meio da aplicação de um questionário em organizações desenvolvedoras de software. O objetivo deste questionário é identificar características da Gerência de Portfólio de Projetos nestas organizações e, para isto, as perguntas foram definidas de acordo com os Resultados Esperados (R.E.) do processo de Gerência de Portfólio de Projetos (GPP) do MR-MPS. Vale ressaltar que esta pesquisa foi iniciada em Abril/2011, logo está em conformidade com a versão 2009 do referido modelo. O Quadro 1 apresenta os itens do questionário e os R.E. relacionados, quando houver.

\section{Quadro 1. Relação entre os R.E. e os Itens do Questionário}

\begin{tabular}{|c|c|}
\hline R.E. do Processo de GPP [Softex, 2009] & Itens do Questionário \\
\hline Não há R.E. relacionado & $\begin{array}{l}\text { 1. As metas e objetivos estratégicos da } \\
\text { organização são registrados em algum documento? }\end{array}$ \\
\hline $\begin{array}{l}\text { GPP 1. As oportunidades de negócio, as } \\
\text { necessidades e os investimentos são identificados, } \\
\text { qualificados, priorizados e selecionados }\end{array}$ & $\begin{array}{l}\text { 2. Como são selecionadas as oportunidades } \\
\text { de negócio ou propostas de projetos candidatas a } \\
\text { integrar o portfólio de projetos da organização? } \\
\text { Quais critérios são adotados? }\end{array}$ \\
\hline & $\begin{array}{l}\text { 3. Como os projetos selecionados são } \\
\text { priorizados? Quais critérios são considerados? }\end{array}$ \\
\hline & $\begin{array}{l}\text { 4. Como as atividades dos questionamentos } \\
\text { anteriores se adéquam ou refletem os objetivos } \\
\text { estratégicos da organização? }\end{array}$ \\
\hline $\begin{array}{l}\text { GPP 2. Os recursos e orçamentos para cada projeto } \\
\text { são identificados e alocados }\end{array}$ & $\begin{array}{l}\text { 5. Como são asseguradas a identificação e a } \\
\text { alocação dos recursos (pessoas, instalações, } \\
\text { ferramentas, entre outros) e orçamento necessários } \\
\text { para a execução dos projetos? }\end{array}$ \\
\hline $\begin{array}{l}\text { GPP 3. A responsabilidade e autoridade pelo } \\
\text { gerenciamento dos projetos são estabelecidas }\end{array}$ & $\begin{array}{l}\text { 6. Como são definidas a autoridade e a } \\
\text { autonomia necessárias para a gestão dos projetos } \\
\text { selecionados? }\end{array}$ \\
\hline $\begin{array}{l}\text { GPP 4. Os conflitos sobre recursos entre projetos } \\
\text { são tratados e resolvidos }\end{array}$ & $\begin{array}{l}7 . \quad \text { Como são tratados os conflitos em } \\
\text { relação a recursos compartilhados entre os } \\
\text { projetos? }\end{array}$ \\
\hline $\begin{array}{l}\text { GPP 5. Projetos que atendem aos acordos e } \\
\text { requisitos que levaram à sua aprovação são } \\
\text { mantidos, e os que não atendem são redirecionados } \\
\text { ou cancelados }\end{array}$ & $\begin{array}{l}8 . \quad \text { É conduzida alguma atividade para } \\
\text { verificar se os projetos em execução continuam em } \\
\text { conformidade com os objetivos estratégicos da } \\
\text { organização e/ou aos demais critérios que } \\
\text { motivaram sua seleção? Como isso é feito? Que } \\
\text { decisões são tomadas? }\end{array}$ \\
\hline Não há R.E. relacionado & A organização mantém seus projetos \\
\hline
\end{tabular}




\begin{tabular}{|l|l|}
\hline R.E. do Processo de GPP [Softex, 2009] & \multicolumn{1}{c|}{ Itens do Questionário } \\
\hline & $\begin{array}{l}\text { organizados em mais de um portfólio? Se sim, por } \\
\text { quê? } \\
10 . \quad \text { As atividades descritas anteriormente } \\
\text { estão formalmente definidas em um processo e } \\
\text { institucionalizado na organização? Tal processo foi } \\
\text { inspirado e está em conformidade com algum } \\
\text { modelo de qualidade, norma, padrão ou afim? } \\
11 . \quad \text { Quais os papéis (perfis) organizacionais } \\
\text { estão envolvidos no processo em questão? }\end{array}$ \\
\hline
\end{tabular}

Como população da pesquisa, foram selecionadas organizações desenvolvedoras de software, identificando para cada uma delas o porte, qual o tipo de organização (pública ou privada), e qual o tipo de serviço ou produto desenvolvido. Além destas características, tomou-se nota do papel ou função exercida pelo indivíduo que realizou o preenchimento do questionário em nome da organização.

Optou-se por não identificar se as organizações haviam sido submetidas a avaliações oficiais do MPS.BR, uma vez que, conforme publicado oficialmente em Softex (2012), nenhuma organização da Região Norte havia sido avaliada no Nível F de maturidade no período entre 2009 (ano de inclusão do processo de GPP no nível F do MR-MPS) e o início da condução deste estudo.

Os questionários foram enviados em Abril/2011 a vinte organizações da região Norte (considerando as cidades: Belém, Manaus e Macapá). Contudo, apenas organizações da região metropolitana de Belém retornaram o questionário preenchido. Desta forma, este estudo apresenta uma abrangência parcial da real situação da região Norte, logo se optou por restringir o escopo da análise à Belém, e não à região Norte em sua totalidade.

Os resultados foram analisados de forma qualitativa, não procurando avaliá-los em relação à aderência ao MPS.BR, mas sim com o objetivo de caracterizar práticas realizadas no contexto de gestão de portfólio de projetos. Em seguida, adotou-se o estudo realizado por Souza et al.(2011) a fim de comparação entre as práticas adotadas pelas organizações investigadas e o conjunto de boas práticas levantadas pelo estudo citado.

\section{Resultados da Aplicação dos Questionários}

Por questão de confidencialidade, conforme acordado com as organizações que se submeteram ao estudo, nenhuma informação que permita a identificação da organização ou de seus membros será informada. Para tanto as organizações serão identificadas por letras, de "A" à "I" (nove organizações ao total). O Quadro 2 relaciona o perfil de cada organização, descrevendo tipo, porte e projetos desenvolvidos.

Quadro 2. Perfil das Organizações Submetidas ao Estudo

\begin{tabular}{|c|c|c|c|c|}
\hline ID & TIPO & PORTE & TIPO DE PROJETOS & $\begin{array}{c}\text { PAPEL DO(S) } \\
\text { ENTREVISTADO(S) }\end{array}$ \\
\hline A & Pública & Pequena & $\begin{array}{c}\text { Tecnologia de Informação/ } \\
\text { Desenvolvimento de Sistemas }\end{array}$ & $\begin{array}{c}\text { Chefe do desenvolvimento de } \\
\text { sistemas }\end{array}$ \\
\hline B & & & Desenvolvimento, manutenção e & $\begin{array}{c}\text { Coordenador de Sistemas de } \\
\text { Informação (responsável pelas }\end{array}$ \\
\hline
\end{tabular}




\begin{tabular}{|c|c|c|c|c|}
\hline ID & TIPO & PORTE & TIPO DE PROJETOS & $\begin{array}{c}\text { PAPEL DO(S) } \\
\text { ENTREVISTADO(S) }\end{array}$ \\
\hline Pública & Médio & implantação de sistemas & $\begin{array}{c}\text { equipes de desenvolvimento, } \\
\text { implantação e manutenção de } \\
\text { software) e Analista de } \\
\text { Tecnologia (gerente de } \\
\text { projetos) }\end{array}$ \\
\hline C & Privada & Pequeno & $\begin{array}{c}\text { Desenvolvimento de aplicações Web } \\
\text { com foco em Operadoras de } \\
\text { Telefonia Móvel e seus parceiros }\end{array}$ & $\begin{array}{c}\text { Gerente de Projetos, } \\
\text { Desenvolvedor e Entrevistador }\end{array}$ \\
\hline D & Privada & Pequeno & $\begin{array}{c}\text { Desenvolvimento de Sistemas de } \\
\text { Software }\end{array}$ & $\begin{array}{c}\text { Coordenador da Fábrica de } \\
\text { Software }\end{array}$ \\
\hline E & Pública & Grande. & $\begin{array}{c}\text { Serviços e Desenvolvimento voltados } \\
\text { à prestação jurisdicional }\end{array}$ & $\begin{array}{c}\text { Secretário de Tecnologia da } \\
\text { Informação e Coordenador de } \\
\text { Educação e Desenvolvimento }\end{array}$ \\
\hline F & Pública & Médio & Desenvolvimento de Soluções & Coordenador de Aplicações \\
\hline H & Pública & Médio & $\begin{array}{c}\text { Desenvolvimento de sistemas web } \\
\text { para uso interno }\end{array}$ & $\begin{array}{c}\text { Gestor do setor responsável } \\
\text { pela garantia da qualidade de } \\
\text { software, coordenador da célula } \\
\text { de testes, coordenador do grupo } \\
\text { de engenharia de software. }\end{array}$ \\
\hline Pública & Grande & $\begin{array}{c}\text { Desenvolvimento e implementação } \\
\text { de sistemas de software }\end{array}$ & $\begin{array}{c}\text { Analista de Sistemas } \\
\text { para o Governo Federal, desde a } \\
\text { montagem de infra-estrutura de } \\
\text { comunicações ao desenvolvimento e } \\
\text { manutencones de sistemas }\end{array}$ \\
\hline
\end{tabular}

As subseções seguintes relatam a análise dos resultados obtidos para cada questão (listadas no Quadro 1). Não é objetivo deste estudo avaliar quais práticas utilizadas são mais adequadas ou avaliar a conformidade com o MR-MPS, mas sim investigar o que é realizado e de forma geral avaliar possíveis pontos de melhoria.

\subsection{Questão 1}

A respeito da definição de objetivos estratégicos ou metas das organizações, observouse que a maioria das organizações submetidas ao estudo registram de alguma forma estas informações, que são o alicerce para que a gestão de portfólio esteja alinhada ao planejamento estratégico organizacional.

As organizações $\mathbf{A}$ e $\mathbf{C}$ relataram não haver registro sobre os objetivos organizacionais da organização. Enquanto as organizações $\mathbf{B}, \mathbf{D}, \mathbf{E}, \mathbf{F}, \mathbf{G}, \mathbf{H}$ e I afirmaram que existe documentação dos objetivos estratégicos da organização.

A organização $\mathbf{B}$ mencionou a existência de um documento denominado Plano Diretor de Tecnologia da Informação (PDTI), no qual constam os objetivos estratégicos da empresa, possuindo validade de 2 a 10 anos (coincidente à época de aplicação do questionário, o PDTI da organização estava sendo finalizado, para os anos de $2011 \mathrm{e}$ 2012). Também foi mencionada a elaboração, com vigência de 1 ano, do Plano de Metas da organização, que deve estar em consonância com o PDTI.

Nas organizações $\mathbf{E}$ e $\mathbf{G}$ foi mencionado que seus objetivos estratégicos são descritos, respectivamente, nos documentos "Plano Estratégico Institucional" e "PGP Plano de Gestão do Processo". 
Na organização D existe a definição de Missão, Visão, Valores e Princípios organizacionais, porém não estão claramente definidas (documentados) metas ou objetivos estratégicos.

\subsection{Questão 2}

Em relação ao processo e critérios de seleção de projetos, as respostas foram variadas. A organização B destacou a concordância com dos objetivos da proposta de negócios/projetos com os objetivos da Instituição no qual a organização está inserida, ou seja, a abrangência dos benefícios de tal proposta para a Instituição como um todo. Dessa forma, os projetos são selecionados a partir das decisões da Administração Superior da Instituição. Demais critérios apontados pela organização B incluem: relevância do projeto, disponibilidade de recursos humanos e/ou financeiros, capacidade da equipe.

A organização D descreveu que o processo de seleção de projetos acontece de forma empírica, tendo como critérios a aderência à missão, visão, valores e princípios organizacionais, além de critérios relacionados à inovação, viabilidade técnica e complexidade (o que também se relaciona com a capacidade das equipes), disponibilidade de recursos, visibilidade e motivação da equipe. Adicionalmente, existem categorias de projeto (Internos e Externos). Além disso, há uma breve identificação de possíveis riscos (mas não há analise ou acompanhamento dos mesmos). Semestralmente é verificada a possibilidade de inclusão de novos projetos, adequando as atividades da organização em relação à oscilação das equipes. Mudanças no portfólio são comunicadas às instâncias superiores semestralmente

A organização $\mathbf{C}$ mencionou que a avaliação sobre o domínio do conhecimento e da regra de negócio são realizados de acordo com o foco estabelecido pela organização. A organização I apontou o critério de conformidade com o estatuto social da empresa, que determina os negócios que podem ser executados.

A organização $\mathbf{E}$ alegou que a formalização do portfólio da organização ainda estava em andamento.

Pode ser observado que, em parte das organizações, existem critérios variados (estratégicos, técnicos, qualitativos e financeiros) para a seleção de projetos, no entanto há pouca formalização do processo de seleção, o que pode impactar em falta de objetividade. Além disso, a falta de registro dos motivos que levaram a seleção dos projetos pode dificultar o posterior acompanhamento do portfólio, na averiguação se o investimento continua justificado em relação aos critérios de seleção dos projetos.

\subsection{Questão 3}

A priorização dos projetos na organização B é primariamente influenciada pela relevância do projeto em relação à conformidade com os objetivos da Instituição, ou seja, o grau de urgência determinado pela Administração Superior determina a maior prioridade. Adicionalmente, critérios que impactam na priorização de projeto são: tempo na fila, criticidade/urgência, fatores políticos. Dependendo do contexto do projeto, os pesos destes critérios podem ser alterados.

$\mathrm{Na}$ organização $\mathbf{E}$ os projetos, de desenvolvimento de sistemas, são priorizados de acordo com uma matriz de pontuação que quantifica o grau de importância para a 
organização. As demais categorias de projetos ainda não possuem uma definição deste caso (fica evidente a distinção de categorias de projetos).

$\mathrm{Na}$ organização $\mathbf{F}$ a priorização de projetos é realizada de acordo com a importância do projeto para as atividades fim da instituição da qual faz parte. De forma semelhante, os projetos da organização $\mathbf{H}$ são priorizados de acordo com a necessidade de urgência determinada pelo coordenador de TI juntamente com a administração da Instituição

As organizações $\mathbf{C}$ e $\mathbf{I}$ adotam uma perspectiva financeira para determinar a prioridade dos seus projetos. A primeira apontou o retorno do investimento como critério de priorização, enquanto a segunda mencionou os critérios custo, investimento, margem e retorno.

A organização D prioriza os seus projetos primariamente pela possibilidade de retorno financeiro, em seguida pelos mesmos critérios de seleção (visibilidade, viabilidade, recursos, motivação da equipe, inovação). No entanto esses critérios são avaliados com base na experiência do coordenador da organização, não havendo um processo objetivo.

Novamente observou-se que critérios são definidos, mas há carência de procedimentos objetivos para aplicação dos critérios e registro das decisões. Um ponto positivo é que em parte das organizações a priorização ocorre em conformidade com objetivos estratégicos e benefícios para a organização.

\subsection{Questão 4}

Com exceção das organizações $\mathbf{A}$ e $\mathbf{G}$, as organizações afirmaram que os projetos estão alinhados de alguma forma aos objetivos da organização, mas não deixaram claro se existe uma forma de validar ou documentar isto. Os projetos selecionados na organização $\mathbf{F}$ passam a compor um o plano estratégico da organização. A organização I valida a conformidade dos seus projetos com os objetivos da organização a partir do alinhamento com o estatuto social da organização procurando maximizar o lucro e eleger atividades compatíveis com sua capacidade de investimento. A organização $\mathbf{H}$ menciona a compatibilidade com objetivos estratégicos registrados no planejamento da Instituição.

\subsection{Questão 5}

A respeito da identificação de orçamento e alocação de recursos para os projetos, a organização I aponta a realização de um orçamento anual onde é realizada a estimativa de negócios e recursos, enquanto a organização $\mathbf{C}$ aponta a condução de uma "avaliação técnica básica" para determinar as necessidades do projeto.

$\mathrm{Na}$ organização $\mathbf{B}$, os recursos disponíveis são identificados durante o planejamento do projeto, e o gerente de projetos possui a liberdade para alocar os recursos da melhor forma possível. Suas decisões são, então, enviadas à Administração Superior, de modo que a viabilidade do projeto seja discutida, e o projeto possa ser, então, aprovado para execução. Vale ressaltar duas informações encontradas nos questionários: os colaboradores, ou indivíduos responsáveis pela execução do projeto, são alocados de acordo com suas habilidades listadas no Plano da Organização, e caso já estejam alocados, porém em projetos de menor complexidade, podem ser realocados 
para projetos maiores, de acordo com a necessidade; com relação a recursos financeiros, para projetos de software, os custos são considerados de acordo com as horas decorrentes de sua execução, mas no âmbito da organização em questão, estes devem se enquadrar no orçamento anual disponível.

Na organização $\mathbf{D}$ cada projeto é financiado por uma fonte própria de recursos. Em relação aos recursos humanos, a organização é composta por equipes entre as quais os projetos são distribuídos conforme suas habilidades. Há registro da alocação de recursos humanos, no entanto um problema reportado pela própria organização é a falta de registro sobe o remanejamento estratégico de recursos entre projetos.

As organizações $\mathbf{F}$ e $\mathbf{H}$ enfatizaram a falta de um planejamento para a alocação dos recursos sendo este realizado conforme a necessidade dos projetos.

O principal objetivo da alocação de recursos no contexto da gestão de portfólio é promover uma estratégia que melhor atenda as necessidades de cada projeto, mas que considere primariamente a prioridade destes para a organização, em geral refletindo investimento prioritário nos projetos que apresentam maior potencial de retorno de benefícios. Nenhuma organização relatou a relevância da prioridade dos projetos, mas sim a necessidade de recursos de cada projeto.

\subsection{Questão 6}

Não organização B, o gerente de projetos possui a autonomia necessária para a gestão dos projetos, de acordo com o seu nível de conhecimento a respeito das regras de negócio a serem aplicadas como produto final. Quanto à sua escolha, dois procedimentos foram mencionados: (i) a escolha é feita através do consenso entre os próprios gerentes de projeto, de acordo com a disponibilidade de cada um, e o gerente responsável é registrado no Termo de Abertura do projeto; e (ii) que os gerentes são definidos pelo próprio chefe da divisão, que avalia os perfis das pessoas disponíveis e atribui a elas o papel de gerente (essas definições ficam explícitas em diversos documentos do projeto). Nota-se uma falta de padronização a respeito desta ação.

$\mathrm{Na}$ organização $\mathbf{D}$, a seleção dos responsáveis por projetos (papel de líder de projeto) é feita pelo coordenador da organização conforme a disponibilidade e sobretudo experiência e habilidade dos indivíduos. O responsável por cada projeto é evidenciado no Artefato de Visão de Escopo. De forma semelhante, na organização C a responsabilidade e autonomia sobre a gestão do projeto é determinada a partir dos critérios: conhecimento técnico, confiança pessoal e tempo de serviço.

As organizações $\mathbf{E}$ e $\mathbf{H}$ são menos enfáticas sobre esta definição, sendo que na primeira a responsabilidade da gestão dos projetos cabe ao chefe de cada setor administrativo da organização, enquanto na segunda há um revezamento da equipe de desenvolvimento na escolha do gerente de projetos.

A organização I apenas relatou que esta decisão é registrada no momento do início de cada projeto, quando são registrados no Portal de Projetos da organização.

\subsection{Questão 7}

O tratamento de conflitos sobre recursos dos projetos é tratado levando em consideração a prioridade dos projetos nas organizações $\mathbf{B}, \mathbf{C}$ e I. Em B, caso seja detectado conflito, é identificado se existem outros recursos disponíveis. Caso não, a questão é levada à 
Administração Superior para análise e escolha dos projetos mais prioritários, e que necessitam de maior quantidade de recursos (realocação de recursos). Para o colaborador, deve ser levada em conta sua carga horária e se este possui disponibilidade para ser alocado a mais de um projeto ou, se for o caso, realocado a novos projetos. De forma semelhante, a organização I menciona a resolução por meio da Diretoria Executiva conforme a relevância.

A organização C menciona os critérios "grau de relevância", "urgência" e "retorno do investimento", como norteadores para tomadas de decisão a respeito de resolução de conflitos e necessidade de remanejamento de recursos entre projetos. A organização $\mathbf{E}$ apenas respondeu que qualquer conflito é solucionado pela Direção Geral.

Para a D, os conflitos de recurso ocorrem principalmente no que tange à alocação de líderes de projeto na coordenação de múltiplos projetos. Problemas ocorridos são tratados por meio de reuniões, mas não há nenhum registro ou formalismo envolvido.

Percebeu-se que as organizações têm conhecimento do acontecimento de conflitos e tomam ações para tratá-los, mas não há um acompanhamento desta resolução, tão pouco um registro para definir uma base histórica ou monitorar se a solução de fato foi atingida.

\subsection{Questão 8}

O acompanhamento do portfólio é realizado pelas organizações $\mathbf{B}, \mathbf{C}, \mathbf{D}, \mathbf{E}$ e I. Segundo o relato fornecido pela organização $\mathbf{B}$, são realizadas reuniões mensais com a Direção, de modo a manter um controle sobre o andamento dos projetos em execução, durante marcos do projeto. Esses encontros são realizados com a participação do gerente de projetos, e do patrocinador, na forma da Instituição na qual se insere a organização. É, então, decidido se o projeto deve ser continuado, pausado ou cancelado. As decisões são tomadas de forma ad hoc, de modo que são consideradas mais as situações cotidianas que a observância aos objetivos estratégicos.

A organização $\mathbf{C}$ relata que esse acompanhamento é realizado por meio de reuniões periódicas para se aferir e retificar e/ou ratificar se os objetivos continuam alinhados com os objetivos iniciais, com a priorização de um projeto em relação a outro.

Não há monitoramento dos projetos em relação aos critérios que levaram a sua seleção na organização D. Contudo, projetos são monitorados quanto ao desempenho, tendo como referência, principalmente, o esforço estipulado para cada sprint. Possíveis desvios são identificados, porém não são registrados. Ações para correção de desvios identificadas são tomadas em reuniões com a equipe, mas não há nenhum formalismo envolvido, e não são estabelecidas ações para a prevenção da repetição. Conforme o andamento dos projetos, estes podem ser cancelados, redirecionados ou mantidos. Há o registro do estado dos projetos no documento de visão e escopo dos mesmos, porém não é feito registro das justificativas/circunstâncias que levaram a decisão. Semestralmente é feito um relatório para a pró-reitoria da instituição, onde a organização D se insere, sobre os projetos da organização e suas respectivas situações

Em E, a cada semestre é feita uma reavaliação da pauta de desenvolvimento de projetos de desenvolvimento de sistemas. Já na organização I, é feito o 
acompanhamento do faturamento/custos/margem e analisada a evolução do produto periodicamente pela área de controles internos e contadoria.

Não houve muitos indícios de uma análise objetiva, com critérios bem definidos ou que reflitam os objetivos estratégicos ou critérios que justificaram a seleção do projetos em primeiro lugar, salvo as organizações $\mathbf{C}$ e $\mathbf{I}$ que relatou que seus critérios de seleção são acompanhados ao longo da execução do projeto. Apenas duas organizações (B e D) indicaram tomadas de decisões a respeito de redirecionar ou interromper projetos conforme resultados do acompanhamento dos projetos, e apenas uma organização mencionou a identificação e tratamento de desvios do portfólio (D) e comunicação do estado dos projetos a instancias superiores.

\subsection{Questão 9}

Observou-se que as organizações mantém apenas um portfólio de projetos, onde os projetos são divididos em categorias (caso de B e D) ou são administrados por unidade de negócio (caso de $\mathbf{I}$ ). A organização $\mathbf{E}$ mencionou que a definição do portfólio da organização ainda está em fase de estudo.

\subsection{Questão 10}

Quando indagadas a respeito da definição e institucionalização de um processo para gestão de portfólio, apenas a organização I afirmou que faz uso. Nesta organização, existe o sistema de projetos e propostas onde a oportunidade, cadastrada de acordo com a competência e alçada, segue o fluxo de aprovação/condução. A organização tem estrutura por unidade de negócios. A gestão do portfólio de produtos é feita por cada unidade de negócios. Em relação à adoção de algum padrão ou modelo, a proposta de Mattar e Santos (2003) está ligado à execução. A gestão do portfólio e por consequência do ciclo de vida do produto está relacionado ao aspecto comercial da gestão.

As demais organizações foram unânimes quanto a não existência de um processo definido, apenas documentos "avulsos", conforme apontado pela organização B, que subsidiam a tomada de decisões a respeito da gerência de portfólio de projetos. Tal afirmação faz sentido ao analisar as demais questões respondidas, notando a predominância de métodos empíricos e procedimentos ad-hoc.

\subsection{Questão 11}

Quando indagados sobre os papéis envolvidos na gestão de portfólio de projetos, as respostas foram variadas, mas se percebeu que em geral a alta administração das organizações está diretamente envolvida no processo.

A organização B citou: gerente de projetos; o patrocinador de projetos, na forma da Alta Direção ou Administração Superior, já que o processo de GPP não é definido na organização; Diretor; Conselho Diretivo; Coordenadores; Chefes de Divisão; Funcionários; e Bolsistas.

A organização $\mathbf{C}$ citou apenas gerentes, não sendo claro que tipo de gerentes. Em D: Coordenador da fábrica de software e gerente de projetos (coordenador de unidade). Em E: Assessores; Secretários; Coordenadores; e Chefes de Seção.

De forma mais detalhada, a organização I relatou: Gerente de contas (capta a oportunidade); Gerente executivo (aprova a entrada do projeto); Gestor técnico 
(especifica e gera as informações para precificação); Gestor de Precificação (determina o preço mínimo); Gerente de contas (elabora a proposta); Gerente Executivo e diretor (aprovam a proposta e de acordo com o valor é encaminhada para aprovação do presidente e do conselho administrativo).

A organização $\mathbf{H}$ respondeu que não há papéis claramente definidos na organização, porém geralmente toda a equipe de desenvolvimento está envolvida.

\subsection{Análise e Considerações sobre os Resultados}

Os resultados apontam um baixo nível de padronização e institucionalização de um processo de gestão de portfólio de projetos. Na maior parte dos resultados observou-se carência na objetividade das atividades e documentação ou registro de ações realizadas ou ações tomadas. Em geral, existem critérios para a seleção e priorização de projetos, o que muitas vezes estava em conformidade com os objetivos e metas organizacionais, porém foi pouco relatada a existência de um procedimento objetivo para aplicação e garantia da conformidade a estes critérios.

A gestão dos recursos organizacionais não é planejada de forma a maximizar o potencial de atendimento aos objetivos estratégicos das organizações, mas sim com o foco de suprir as necessidades de cada projeto, sem que tenha sido mencionado que a prioridade dos projetos é considerada.

Cinco organizações mencionaram o tratamento de conflitos na alocação de recursos entre projetos e, destas, apenas três mencionaram considerar a prioridade dos projetos para tratar estes desvios. No entanto, não houve relatos sobre como esses conflitos são acompanhados, apenas sobre como são resolvidos, o que normalmente envolvia a decisão da alta administração.

Quanto ao acompanhamento dos portfólios, a maioria dos resultados apontou que é realizado do ponto de vista do andamento dos projetos individualmente, havendo apenas duas organizações que mencionaram a avaliação dos projetos em relação aos critérios que levaram a aprovação destes. Pouco foi relatada a respeito da identificação de desvios e ações de contingência ou mitigação. Foi observado, no entanto, que há tomada de decisão a partir destas avaliações, sobre continuar, redirecionar ou parar projetos.

Optou-se por manter as organizações A e $\mathbf{G}$ nos resultados de pesquisa, muito embora tenham respondido não realizar (no caso de $\mathbf{A}$ ) ou o entrevistado não ter propriedade para comentar (no caso de $\mathbf{G}$ ) as práticas investigadas no questionário, uma vez que estes resultados apontam baixa maturidade em gestão de portfólio e a falta de institucionalização de um processo para gerenciar o portfólio organizacional.

\section{Comparação Com Mapeamento}

Em Souza et al. (2011) uma análise é conduzida sobre as práticas de gerência de portfólio de projetos sugeridas pelos modelo MR-MPS [SOFTEX, 2011], pela norma ISO/IEC 12207:2008 [ABNT, 2009] e pelo Padrão para Gerência de Portfólio do PMI [PMI, 2008]. Um mapeamento foi realizado visando identificar as convergências entre os modelos e os pontos de diferença, então um conjunto de boas práticas foi estabelecido, representando o conjunto união das práticas envolvidas nos referidos padrões. 
O Quadro 3 lista as práticas levantadas no referido estudo e identifica quais organizações mencionaram-as direta ou indiretamente na pesquisa conduzida. Vale ressaltar que o questionário aplicado não foi concebido para ser aderente a este mapeamento, porém indica algumas das práticas identificadas e pode apontar necessidades de melhoramento.

Quadro 3. Comparação dos Resultados da aplicação dos Questionários com os Resultados de Pesquisa de Souza et al. (2011)

\begin{tabular}{|c|c|}
\hline Boa Prática [Souza et al, 2011] & $\begin{array}{c}\text { Organizações que Mencionaram Práticas } \\
\text { Relacionadas nos Resultados Observados a } \\
\text { partir da Aplicação dos Questionários }\end{array}$ \\
\hline Identificar Projetos candidatos & $\mathrm{B}, \mathrm{C}, \mathrm{D}, \mathrm{E}, \mathrm{F}, \mathrm{H}, \mathrm{I}$ \\
\hline Categoriza Projetos Candidatos & $\mathrm{B}, \mathrm{D}, \mathrm{I}$ \\
\hline Avaliar Projetos Candidatos & E, I \\
\hline Selecionar Projetos Candidatos & $\mathrm{B}, \mathrm{C}, \mathrm{D}, \mathrm{I}$ \\
\hline Identificar Riscos do Portfólio & $\mathrm{D}$ \\
\hline \multicolumn{2}{|l|}{ Analisar Riscos do Portfólio } \\
\hline Priorizar Projetos Candidatos & $\mathrm{B}, \mathrm{C}, \mathrm{D}, \mathrm{E}, \mathrm{F}, \mathrm{H}, \mathrm{I}$ \\
\hline \multicolumn{2}{|l|}{ Desenvolver Resposta aos Riscos do Portfólio } \\
\hline Balancear Portfólio & $\mathrm{B}, \mathrm{C}, \mathrm{D}$ \\
\hline Comunicar Mudanças no Portfólio & $\mathrm{D}, \mathrm{I}$ \\
\hline Definir responsabilidades sobre projetos & $\mathrm{B}, \mathrm{C}, \mathrm{D}, \mathrm{E}, \mathrm{H}, \mathrm{I}$ \\
\hline \multicolumn{2}{|l|}{$\begin{array}{l}\text { Identificar Resultados Esperados dos Projetos } \\
\text { Selecionados }\end{array}$} \\
\hline Alocar Recursos para os Projetos Selecionados & $\mathrm{B}, \mathrm{C}, \mathrm{D}, \mathrm{E}, \mathrm{I}$ \\
\hline $\begin{array}{l}\text { Identificar Possíveis Conflitos de Alocação de } \\
\text { Recursos (Previamente) }\end{array}$ & $\mathrm{B}, \mathrm{D}, \mathrm{I}$ \\
\hline $\begin{array}{l}\text { Definir Marcos e Pontos de Revisão para } \\
\text { Acompanhamento do Projeto }\end{array}$ & $\mathrm{B}, \mathrm{C}, \mathrm{D}, \mathrm{E}, \mathrm{I}$ \\
\hline Autorizar o início dos projetos selecionados & $\mathrm{B}, \mathrm{D}, \mathrm{I}$ \\
\hline Monitorar Portfólio & $\mathrm{B}, \mathrm{C}, \mathrm{D}, \mathrm{E}, \mathrm{I}$ \\
\hline \multicolumn{2}{|l|}{ Monitorar e Controlar os Riscos do Portfólio } \\
\hline Realizar Ações para Corrigir Desvios No Portfólio & $\mathrm{D}$ \\
\hline $\begin{array}{l}\text { Tratar e resolver conflitos sobre recursos entre } \\
\text { projetos }\end{array}$ & $\mathrm{B}, \mathrm{C}, \mathrm{D}, \mathrm{E}, \mathrm{I}$ \\
\hline $\begin{array}{l}\text { Manter Projetos Em execução que continuam } \\
\text { aderentes aos Acordos e critérios de seleção }\end{array}$ & $\mathrm{B}, \mathrm{C}, \mathrm{D}, \mathrm{I}$ \\
\hline $\begin{array}{l}\text { Redirecionar, Cancelar ou Suspender projetos que } \\
\text { não se mantenham aderentes aos Acordos e } \\
\text { Critérios de Seleção }\end{array}$ & $\mathrm{B}, \mathrm{D}$ \\
\hline \multicolumn{2}{|l|}{$\begin{array}{l}\text { Identificar mudanças estratégicas que requeiram } \\
\text { rebalanceamento do portfólio }\end{array}$} \\
\hline Encerrar projetos conforme acordos e políticas e & \\
\hline
\end{tabular}




\begin{tabular}{|c|c|}
\hline \multicolumn{1}{|c|}{ Boa Prática [Souza et al, 2011] } & $\begin{array}{c}\text { Organizações que Mencionaram Práticas } \\
\text { Relacionadas nos Resultados Observados a } \\
\text { partir da Aplicação dos Questionários }\end{array}$ \\
\hline procedimentos organizacionais & \\
\hline
\end{tabular}

O Quadro 3 apenas reflete as informações extraídas dos questionários, então não determina que alguma organização necessariamente deixa de realizar alguma prática, apenas ilustra que a prática não foi mencionada nos resultados. Similarmente, as informações apresentadas não avaliam se as práticas mencionadas são realizadas de forma satisfatória ou aderente aos modelos de qualidade de onde foram originadas.

A análise do Quadro 3 aponta que, nas organizações submetidas ao estudo, há indícios de práticas relacionadas à identificação, categorização, avaliação, seleção e priorização de projetos, balanceamento do portfólio, alocação e tratamento de conflitos de recursos entre os projetos selecionados, autorização de projetos, definição de pontos de revisão de portfólio, acompanhamento de portfólio, tratamento de desvios de portfólio e tomadas de decisão, conforme resultado das revisões.

Não foram identificados indícios de práticas relacionadas à gestão de risco de portfólio (apenas identificação), identificação de mudanças estratégicas e encerramento de projetos, conforme procedimentos organizacionais.

A Figura 1, apenas como consolidação dos dados obtidos na pesquisa, relaciona as organizações, caracterizadas pelo seu porte, com o quantitativo de práticas cujos indícios foram identificados.

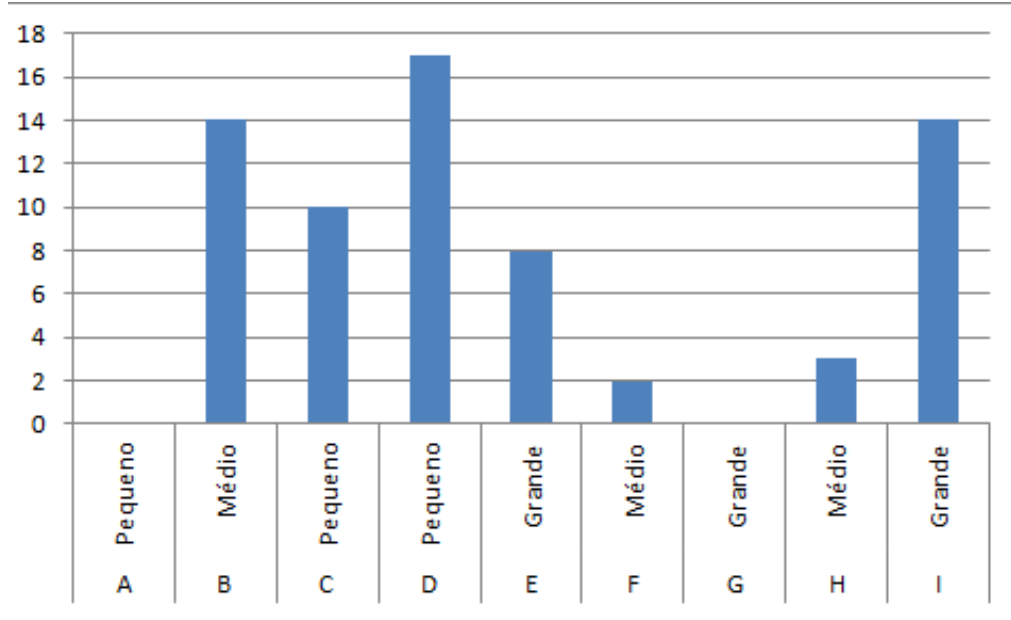

Figura 1. Quantitativo de Boas Práticas por Organização

\section{Conclusões}

Este trabalho apresentou um resultado parcial de uma dissertação de mestrado em desenvolvimento no Programa de Pós-Graduação em Ciência da Computação da Universidade Federal do Pará [SOUZA e OLIVEIRA, 2011]. Foi possível observar que existe carência na definição de um processo formal para a gestão de portfólio e, em consequência, esta atividade é realizada empiricamente e de forma pouco objetiva. Muito embora práticas sejam realizadas, o estudo reafirma o resultado de Costa et al. (2010), identificando uma baixa maturidade em relação a esta disciplina, do ponto de vista da melhoria de processo. 
Para a dissertação onde esta pesquisa insere-se, os resultados obtidos contribuem com o entendimento de quais as limitações práticas da implantação do processo de gerência de portfólio de projetos, bem como a verificação de práticas relacionadas ao mapeamento gerado [Souza et al., 2010]. Este diagnóstico agrega valor em forma de conhecimento sobre as principais deficiências comuns entre as empresas, de tal forma que o framework de processo a ser proposto na referida dissertação possa apontar direcionamentos para contornar tais necessidades. Uma das empresas participantes do estudo foi selecionada para aplicação de um estudo de caso, onde foi definido um processo, com base em um framework de processo proposto na dissertação.

As limitações deste trabalho incluem: (i) resultados obtidos apenas de organizações de software da Região Metropolitana de Belém, muito embora o objetivo inicial fosse abrangir também as cidades de Manaus e Macapá; e (ii) impossibilidade de avaliar o conhecimento prévio dos indivíduos que responderam os questionários, sujeitando os resultados ao entendimento dos mesmos sobre conceitos e práticas de gerência de portfólio de projeto. Uma segunda tentativa de alcançar organizações de outras cidades foi realizada, sem sucesso, na tentativa de contornar a limitação de (i). Foi indicado durante o envio que os questionários deveriam ser preferencialmente respondidos por pessoas que estivessem relacionadas a atividades gestão de portfólio de projetos, com intuito de mitigar a limitação de (ii).

Entre as principais dificuldades encontradas foi convencer as organizações a participarem do estudo, sendo um questionário extenso que abrangia não só a gestão de portfólio, mas também a gestão de recursos humanos (resultados a serem divulgados posteriormente). Nas organizações de Belém, houve a possibilidade de visita para entregar e coletar o questionário em versão impressa, o que aumentou a taxa de retorno. A restrição da análise apenas da Região Metropolitana de Belém impossibilitou generalizar a situação para o contexto da Região Norte, muito embora a situação das organizações apresentadas possa se assemelhar ao cenário de muitas organizações no cenário nacional.

Os resultados obtidos a partir da dissertação em que este estudo está inserido incluem: o mapeamento de boas práticas, utilizado neste artigo, divulgado em Souza et al. (2011); um framework de processo para gerência de portfólio que inclui as boas práticas identificadas no resultado anterior; uma revisão sistemática da literatura acerca das técnicas e ferramentas existentes que contemplem cada boa prática apontada; e um estudo de caso realizado em uma das organizações participantes deste estudo.

\section{Agradecimentos}

Esta pesquisa está vinculada as atividades do grupo de pesquisa do Projeto SPIDER Software Process Improvement: DEvelopment and Research [OLIVEIRA et al., 2011], institucionalizado na Universidade Federal do Pará (UFPA), e é resultado parcial de uma dissertação de mestrado do Programa de Pós-Graduação em Ciência da Computação financiada pelo $\mathrm{CNPq}$, a partir da concessão de bolsa institucional de mestrado e bolsa de iniciação cientifica PIBIC provida pelo CNPq/UFPA. Estendem-se os agradecimentos às organizações e pessoas que aceitaram participar do estudo. 


\section{Referências}

ABNT - ASSOCIAÇÃO BRASILEIRA DE NORMAS TÉCNICAS (2009). "NBR ISO/IEC 12207:2009 - Engenharia de Sistemas de Software - Processos de Ciclo de Vida de Software”. Rio de Janeiro: ABNT, 2009.

COOPER, R.G., EDGETT, S.J, AND KLEINSCHMIDT, E.J., (2001) "Portfolio Management for New Product Development: Results of an Industry Practices Study". R\&D Management - Industrial Research Institute, Inc.Volume 31, number 4, 2001

COSTA, H.R., BARROS, M.O., ROCHA, A.R. (2010) "Maturidade em Gerência de Portfólio de Projetos de Software: um estudo experimental. In: IX Simpósio Brasileiro de Qualidade de Software, Belém - PA."

LEVINE, H.A. (2005), "Project Portfolio Management: A practical guide to selecting projects, managing portfolios and maximizing benefits", San Francisco, Jossey-Bass.

MATTAR, F. N., SANTOS, D. G., (2003) "Gerência de Produtos - como tornar seu produto um sucesso". Editora Atlas, São Paulo.

OLIVEIRA, S. R. B. et al. (2011) "SPIDER - Uma Proposta de Solução Sistêmica de um SUITE de Ferramentas de Software Livre de Apoio à Implementação do Modelo MPS.BR". Revista do Programa Brasileiro da Qualidade e Produtividade em Software. PBQP Software. SEPIN-MCT.

PROJECT MANAGEMENT INSTITUTE - PMI (2008). "The Standard for Portfolio Management”. Syba: PMI Publishing Division. Disponível (para associados) em: $<$ www.pmi.org $>$.

SOFTEX - ASSOCIAÇÃO PARA PROMOÇÃO DA EXCELÊNCIA DO SOFTWARE BRASILEIRO (2009). "Melhoria do Processo de Software Brasileiro (MPS.BR) Guia Geral: 2009”. Disponível em: www.softex.br.

SOFTEX - ASSOCIAÇÃO PARA PROMOÇÃO DA EXCELÊNCIA DO SOFTWARE BRASILEIRO (2011). "Melhoria do Processo de Software Brasileiro (MPS.BR) Guia Geral: 2011”. Disponível em: www.softex.br.

SOFTEX - ASSOCIAÇÃO PARA PROMOÇÃO DA EXCELÊNCIA DO SOFTWARE BRASILEIRO (2012) "Total de organizações com Avaliação MPS (vigentes ou não): quadro-resumo por ano, níveis do MR-MPS e regiões geográficas”. Disponível em: http://www.softex.br/mpsbr/_avaliacoes/default.asp. Última atualização em 2 de Março de 2012.

SOUZA, M. R. A., ARAÚJO, M. V. C., PEREIRA, R. L., OLIVEIRA, S. R. B. (2011). "Um Mapeamento de Boas Práticas de Gerência de Portfólio de Projetos no Contexto da Melhoria do Processo de Software". Anais do $3^{\circ}$ Congresso de Gerenciamento de Projetos da Amazônia-PMI-AM. Manaus, AM.

SOUZA, M. R. A., OLIVEIRA, S. R. B. (2011). "Uma Proposta de Ferramental Livre para Apoio ao Processo de Gerência de Portfólio de Projetos no Contexto de Modelos e Normas de Qualidade de Software". IX Workshop de Teses e Dissertações em Qualidade de Software (WTDQS 2011). Curitiba, PR. 